\title{
Repeat use of emergency contraception: How frequent is it?
}

Judith Roizen, BA PhD, Research Fellow; Ruth Garside, BA MA, Research Fellow, School of Postgraduate Medicine and Health Sciences, University of Exeter; Lisa Barnett, BSc MB ChB MFF, Clinical Coordinator for Family Planning Services, Exeter and District Community NHS Trust (Study Director).

Correspondence: Judith Roizen, Research Fellow, School of Postgraduate Medicine and Health Sciences, University of Exeter, Barrack Road, Exeter, EX2 5AX, UK. Tel: 01392 272986, Fax: 01392 421360, Email:roizen_caston@compuserve.com

(Accepted $16^{\text {th }}$ July 2001)

The Journal of Family Planning and Reproductive Health Care 2001: 27(4): 197-202

\begin{abstract}
Objective. To measure the level of repeat use of emergency contraception (EC) in family planning clinics (FPCs) in North and East Devon.

Design. An audit of repeat use of EC was carried out in seven FPCs, in parallel with a client survey. All women seeking EC in the study period were included $(n=572)$.

Results. Nearly $70 \%$ of women had 'ever' used EC prior to the study visit; over half had previously used EC in the year of the study; a quarter had previously used EC three or more times in the same period. Teenagers were more likely to have previously used EC in the study year, but half of all repeat users were aged 20 and older. Asked why EC was needed today, most women reported current use of regular contraception, but almost a quarter had had unprotected sex, and half reported a condom mishap.

Conclusions. These results show frequent repeat use of EC and do not support recent research based on general practice records, which suggests that repeat use is rare. If EC users use multiple sources of EC, or prefer alternative sources, repeat use of EC will be underestimated if calculated using general practitioner $(G P)$ records alone.
\end{abstract}

\section{Key message points}

- Frequent repeat use of EC was found, in contrast to recent general practice-based research showing that repeat use is 'rare'. Frequent EC users may choose FPCs rather than their GPs. The need for such provision may not currently be met by GPs.

- If EC users use multiple sources of EC, or prefer alternative sources, repeat use of EC will be underestimated if calculated using GP records alone.

- Half of all repeat users were aged 20 and over, although teenagers were more likely to have used EC repeatedly in the study year.

\section{Introduction}

The recent paper of Rowlands et al, ${ }^{1}$ suggesting very low levels of repeat use of emergency contraception (EC) among women seeking EC from their general practice, has generated renewed interest in estimating these levels in other geographic areas and for other providers. Women may use providers other than their GPs and may, in particular, choose to use other providers for repeat requests for EC. GPs may not be informed if EC is obtained from another source. The data from this study of EC use carried out in North and East Devon family planning clinics suggest high levels of repeat use.

The use of EC has increased dramatically in the last decade. A very large number of EC users are teenagers. In 1998, in England as a whole, EC was prescribed on about 0.8 million occasions. ${ }^{2}$ One quarter of these were from family planning clinics (FPCs) and three quarters from GPs. Of the prescriptions from FPCs, half were for teenagers, and a fifth of these teenage EC users were under 16. A 1999 audit of EC use in North and East Devon shows that $45 \%$ of those requesting EC in both FPCs and GP practices were aged 19 or younger. ${ }^{3}$

While repeat use of EC is safe, it is not suitable as a regular method of contraception. ${ }^{4}$ The most recent recommendations from the Faculty of Family Planning and Reproductive Health Care urge that repeat users 'should be warned that the risk of pregnancy when emergency contraception is used repeatedly is likely to be higher than the failure risk of established regular contraception'. In addition, repeat use of EC rather than regular use of other contraceptive methods can put considerable strain on the capacity of health services to accommodate urgent appointments. While pharmacy $(\mathrm{P})$ provision may relieve some of this strain.

Little UK research has focused on repeat use of EC and most has looked at EC use in general practice. Seamark and Pereira Gray, based on a case-note survey in a Devon market town, report that $16 \%$ of 15 -19-year-olds in the practice had consulted for EC. ${ }^{5}$ Of these, a third had consulted more than once. Glazier and Baird, in their study of self-administration of EC, show relatively low levels of repeat use $-12 \%$ in the treatment group in comparison with $13 \%$ in the control group in a 12 -month period. ${ }^{6}$ Rowlands et al, ${ }^{1}$ based on the General Practice Research Database (incorporating records of 95,007 women), report that only $4 \%$ of EC users received EC more than twice in any year. However, between $13 \%$ and $16 \%$ of women received EC more than once in any of the 4 years of the study. The conclusion from this study is that repeat use is 'rare'.

\section{Method}

An audit of repeat use of EC was carried out between the end of October and mid-December 1998 in seven FPCs in North and East Devon. In parallel with the audit a client survey was carried out. Women were asked about current and past use of EC, reasons for its use, use of other contraception, and attitudes towards EC use and provision.

Women seeking EC or given EC (although attending the FPC for another reason e.g. advice) were included $(n=572)$. A one-page questionnaire was filled out by the attending doctor or nurse. Each woman was asked to complete a twopage questionnaire.

All women for whom a staff questionnaire was completed $(\mathrm{n}=572)$ are included in this analysis, whether or not a client questionnaire was completed. Of these the great majority had come for EC $(95.5 \% ; n=546)$. Eleven women had come for other reasons, including advice and/or pregnancy tests. Of these women, seven were given EC. Data on reason for attending was not recorded for 14 women, 13 of whom received EC. Of the women who sought EC, $92.9 \%$ were either supplied with PC4 (96.8\%) or an IUD (3.2\%). One woman received progestogen-only EC.

The client questionnaire was completed by 469 women $(82 \%)$. Most of the women who did not complete the client questionnaire reported that they did not have time to do so. 
However, in a few cases it was noted by staff that a questionnaire was not given out. (The base numbers in tables differ depending on whether the data are taken from the staff or the client questionnaire, and also on whether there are missing data for a variable.) Comparing age distributions for the two questionnaires shows no substantial age differences between the two data sets (Table 1).

Table 1 Age distributions from staff and client questionnaires

\begin{tabular}{ccc}
\hline $\begin{array}{c}\text { Staff questionnaire } \\
\mathbf{n}=\mathbf{5 7 2} \\
\text { (percents) }\end{array}$ & Age & $\begin{array}{c}\text { Client questionnaire } \\
\mathbf{n = 4 6 9} \\
\text { (percents) }\end{array}$ \\
\hline 28.4 & $\mathbf{1 7}$ and younger & 27.7 \\
22.6 & $\mathbf{1 8}-\mathbf{1 9}$ & 23.2 \\
25.2 & $\mathbf{2 0}-\mathbf{2 4}$ & 25.8 \\
13.4 & $\mathbf{2 5}-\mathbf{2 9}$ & 13.6 \\
10.4 & $\mathbf{3 0}$ and older & 9.6 \\
\hline
\end{tabular}

Of the seven participating clinics, Exeter is the only FPC in North and East Devon which holds a daily clinic; $83 \%$ of the participants in the study were Exeter FPC clients, although not all clients of the Exeter clinic live in Exeter (30\% of Exeter FPC users live outside the city boundaries.) Sixty-five percent of women included in the study had previously visited their clinic. In almost all cases, women had come themselves rather than having been referred either by their GP or by accident and emergency.

The staff and client questionnaires were edited and coded by postgraduate students at the Institute of Population Studies, University of Exeter. Data entry was carried out by the University's Information and Technology Services Unit. SPSS v.8.0 was used for the quantitative analysis.

\section{Results}

Background characteristics of study participants

Age. The age distribution of study participants is shown in Table 1. Half of those seeking EC were under 20. Looking in more detail at the full distribution for the youngest age groups: $6.6 \%(n=36)$ were under $16 ; 22.8 \%(n=125)$ were aged $16-17$, and $23.3 \%(n=128)$ were aged $18-19$.

For this analysis women aged 17 and younger are presented as one age group, as the numbers at younger ages are very small.

Primary activity. Reflecting the relative youth of the study participants, half reported that they were in school or at college/university, $14.0 \%$ and $35.3 \%$ respectively. Only $5.1 \%$ of participants reported that they were housewives/ mothers. Nearly a third of the women were in full-time employment which, of course, has implications for their ability to seek an emergency consultation.

Marital status/partnership. Slightly over $80 \%$ of women reported that they had a 'regular partner'. The fact that this percentage varied little across age groups suggests that the definition of what is a 'regular partner' may differ considerably among women.

The majority of women seeking EC were single (75.9\%) with a 'regular partner', including those 'living together' and those who had a 'steady boyfriend', or were divorced $(2.8 \%)$ with a 'regular partner'. Fifteen percent of women indicated that they were single with no regular partner. Only $4.8 \%$ were married.

Reproductive history. A quarter $(\mathrm{n}=117)$ of the women had had a pregnancy. Of these, half $(n=59)$ had ever had an abortion; half $(n=57)$ had had at least one baby and just over $15 \%$ had ever had a miscarriage. However, the study did not include a pregnancy/EC-use history, so use of EC prior to, or after, pregnancies cannot be determined.

\section{Repeat use of EC}

Five questions were asked on use of EC, two in the staff questionnaire and three in the client questionnaire:

From the staff questionnaire:

$\checkmark$ Question 1: Is this the first time you have used EC?

$\checkmark$ Question 2: Have you used EC since $1^{\text {st }}$ January this year?

From the client questionnaire:

$\checkmark$ Question 4: Is today the first time that you have ever used EC?

$\checkmark$ Question 5: Before today, how many times have you used EC since $1^{\text {st }}$ January this year?

$\checkmark$ Question 6: I estimate I have used EC a total of times ever?

The January $1^{\text {st }}$ date was used to give respondents a point of reference to aid recall. Since the study ran for a period of 7 weeks from the end of October, the exposure period for EC use varies. The study year, used below, is not a 12 month year and refers to the year of the study with variable periods of exposure depending on client's date of visit to the clinic. The likely effect of this is to underestimate EC use in the study year.

The study was limited to clinic visits for EC. Use of EC is measured both for 'ever' use and for use in the study year prior to the audited visit. In both instances repeat use is defined as having received EC a minimum of two times.

As shown in Table 2 (based on Q1 and Q4 above), nearly $70 \%$ of women had used EC at least once prior to the audited visit ('ever use'); about a third were first time users. Similar percentages were reported in both the staff and client questionnaires, $67 \%$ and $68 \%$ respectively. Fifty-two percent of those for whom a staff questionnaire was completed reported using EC in the study year, i.e. since $1^{\text {st }}$ January of 1998 (Q2 above). This is the case for $62.8 \%$ of those completing the client questionnaire (Q5 above). The difference between these percentages is due both to the fact that more repeat users completed the client questionnaire, and the fact that some women gave different answers on the two questionnaires. Of those who said 'no' to Q2 above almost a quarter reported using EC in the study year in Q5. While some of these responses may be the result of women's desire to give a response that FPC staff might want to hear, those answering the client questionnaire had more time to consider their response. Some may have found it difficult to remember exactly when they had used EC in the previous months, when asked by the FPC staff.

Table 3a shows the percentages (by age) of women who are first time users. There is a roughly ' $U$ ' shaped distribution shown here, with first use highest amongst the two younger and the oldest age groups. But in all age groups, the majority of women had used EC in the past, including almost two thirds of teenagers aged 17 and younger.

Table 2 Repeat use of EC: Staff/client questionnaire

\begin{tabular}{lcc}
\hline & $\begin{array}{c}\text { First time used EC } \\
\text { (NO) }\end{array}$ & $\begin{array}{c}\text { Used EC this year } \\
\text { (YES) }\end{array}$ \\
\hline Staff (percent) & 67.0 & 52.2 \\
Client (percent) & 68.0 & 62.8 \\
\hline
\end{tabular}


Table 3a First time used EC, by age

\begin{tabular}{|c|c|c|c|c|c|c|}
\hline \multicolumn{7}{|c|}{ Age (years) } \\
\hline & 14-17 & 18-19 & $20-24$ & $25-29$ & 30+ & TOTAL \\
\hline \multirow[t]{2}{*}{ YES } & 55 & 49 & 39 & 18 & 21 & 182 \\
\hline & $35.7 \%$ & $38.9 \%$ & $27.3 \%$ & $25.7 \%$ & $37.5 \%$ & $33.2 \%$ \\
\hline \multirow[t]{2}{*}{ NO } & 99 & 77 & 104 & 52 & 35 & 367 \\
\hline & $64.3 \%$ & $61.1 \%$ & $72.7 \%$ & $74.3 \%$ & $62.5 \%$ & $66.8 \%$ \\
\hline \multirow[t]{2}{*}{ TOTAL } & 154 & 126 & 143 & 70 & 56 & 549 \\
\hline & $100.0 \%$ & $100.0 \%$ & $100.0 \%$ & $100.0 \%$ & $100.0 \%$ & $100.0 \%$ \\
\hline
\end{tabular}

Responses to Q2 above, use of EC in the study year, are also shown (by age) in Table $3 b$. Here the highest percentage of those who have used EC is seen in the youngest age group and the lowest in the oldest age group. Nearly $70 \%$ of young women aged $14-17$ had used EC in the year, in contrast with fewer than $45 \%$ of women in their 20 s.

Table 3b Used EC in study year, by age

\begin{tabular}{lcccccc}
\hline & & \multicolumn{3}{c}{ Age (years) } & & \\
& $\mathbf{1 4 - 1 7}$ & $\mathbf{1 8 - 1 9}$ & $\mathbf{2 0 - 2 4}$ & $\mathbf{2 5 - 2 9}$ & $\mathbf{3 0 +}$ & TOTAL \\
\hline YES & 82 & 49 & 48 & 24 & 10 & 213 \\
& $68.9 \%$ & $57.6 \%$ & $44.9 \%$ & $40.7 \%$ & $25.0 \%$ & $52.0 \%$ \\
NO & 37 & 36 & 59 & 35 & 30 & 197 \\
& $31.1 \%$ & $42.2 \%$ & $55.1 \%$ & $59.3 \%$ & $75.0 \%$ & $48.0 \%$ \\
\multirow{2}{*}{ TOTAL } & 119 & 85 & 197 & 59 & 40 & 410 \\
& $100.0 \%$ & $100 / \%$ & $100.0 \%$ & $100.0 \%$ & $100.0 \%$ & $100.0 \%$ \\
\hline
\end{tabular}

The number of times EC was used in the study year was asked in the client questionnaire (Table 3c). The great majority (77\%) of women previously using EC in the study year reported using it 'once or twice'; however, $6 \%$ reported using it five or more times. Rowlands et al ${ }^{1}$ define repeat use in a year as more than two uses. They report that in none of their four study years did more than $4 \%$ of EC users use EC three or more times. In contrast, this study shows that $23.1 \%$ of those who used EC in the study year used EC three or more times. As the study year is not a 12 month estimate, this measure is likely to be an underestimate of annual use.

The number of times EC was 'ever' used is shown in Table $3 \mathrm{~d}$. Of course, older women have longer exposure to EC. Given this, it is surprising that the differences between the younger and the older women are not greater. Of women in the youngest age group (14-17), 27.6\% reported 'ever' using EC four or more times, contrasted with $34 \%$ of women 25-29 who are a decade older. This may be due to a lack of knowledge of EC in the past as a contraceptive option for the older age group. What is clear is that among

Table 3c This year how many times used EC, by age

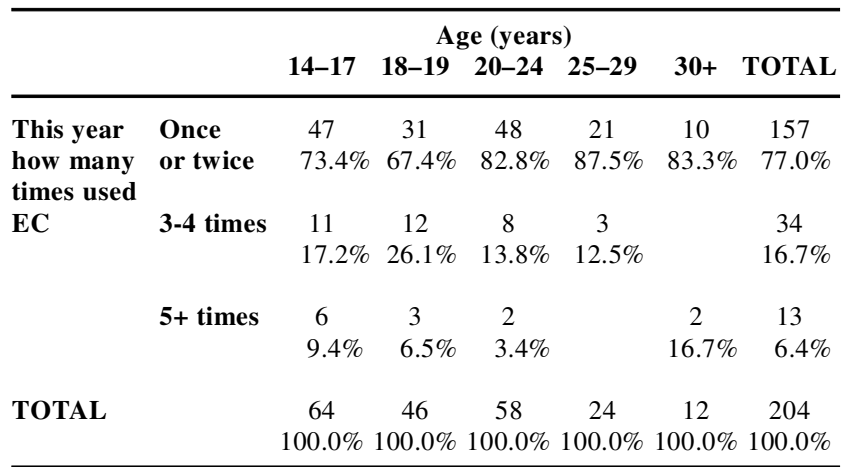

Table 3d Number of times ever used EC, by Age

\section{Age (years)}

14-17 18-19 20-24 25-29 30+ TOTAL

$\begin{array}{llllllll}\text { Times ever } & \text { 1-2 times } & 38 & 35 & 41 & 20 & 12 & 146\end{array}$

used EC

$$
\begin{array}{ccccccc}
3 \text { times } & 17 & 14 & 19 & 11 & 10 & 71 \\
& 22.4 \% & 20.9 \% & 20.7 \% & 23.4 \% & 34.5 \% & 22.8 \% \\
\text { 4+ times } & 21 & 18 & 32 & 16 & 7 & 94 \\
& 27.6 \% & 26.9 \% & 34.8 \% & 34.0 \% & 24.1 \% & 30.2 \%
\end{array}
$$

TOTAL

$\begin{array}{llllll}76 & 67 & 92 & 47 & 29 & 311\end{array}$ $100.0 \% \quad 100.0 \% \quad 100.0 \% \quad 100.0 \% \quad 100.0 \% \quad 100.0 \%$

some younger women there is likely to be an intense period of use of EC before moving to more effective forms of contraception.

Use of contraception: Why EC needed: Hours since unprotected sex

The majority of women ( $84.7 \%$ ) presenting for EC reported that they were using some form of contraception. The methods used are shown in Table 4. Over three quarters of

\begin{tabular}{|c|c|c|c|c|c|c|}
\hline \multirow[t]{2}{*}{ Method } & \multicolumn{5}{|c|}{ Age } & \multirow[b]{2}{*}{ Total } \\
\hline & $14-17$ & $18-19$ & $20-24$ & $25-29$ & $30+$ & \\
\hline \multirow[t]{2}{*}{ None } & 30 & 16 & 16 & 12 & 12 & 86 \\
\hline & $18.8 \%$ & $12.6 \%$ & $11.3 \%$ & $15.8 \%$ & $20.7 \%$ & $15.3 \%$ \\
\hline \multirow[t]{2}{*}{$\mathrm{COC}$} & 18 & 27 & 22 & 10 & 4 & 81 \\
\hline & $11.2 \%$ & $21.3 \%$ & $15.5 \%$ & $13.2 \%$ & $6.9 \%$ & $14.4 \%$ \\
\hline \multirow[t]{2}{*}{ POP } & 3 & 1 & 5 & 3 & 2 & 14 \\
\hline & $1.9 \%$ & $0.8 \%$ & $3.5 \%$ & $3.9 \%$ & $3.4 \%$ & $2.5 \%$ \\
\hline \multirow[t]{2}{*}{ Condom } & 108 & 79 & 94 & 48 & 36 & 365 \\
\hline & $67.1 \%$ & $62.2 \%$ & $66.2 \%$ & $63.2 \%$ & $62.1 \%$ & $64.5 \%$ \\
\hline \multirow[t]{2}{*}{ Depo Provera } & - & - & 2 & - & - & 2 \\
\hline & & & $1.4 \%$ & & & $0.4 \%$ \\
\hline \multirow[t]{2}{*}{ Cap/Diaphragm } & 一 & 1 & - & 3 & 3 & 7 \\
\hline & & $0.8 \%$ & & $3.9 \%$ & $5.2 \%$ & $1.2 \%$ \\
\hline \multirow[t]{2}{*}{ Multiple } & 1 & 3 & 3 & - & 1 & 8 \\
\hline & $0.6 \%$ & $2.4 \%$ & $2.1 \%$ & & $1.7 \%$ & $1.4 \%$ \\
\hline \multirow[t]{2}{*}{ Total } & 160 & 127 & 142 & 76 & 58 & 563 \\
\hline & $100 \%$ & $100 \%$ & $100 \%$ & $100 \%$ & $100 \%$ & $100 \%$ \\
\hline
\end{tabular}
women currently using contraception reported that they were using condoms.

Table 4 Current method of contraception of EC users, by age

The majority of repeat users also reported that they were using some form of contraception (87.9\% of those whose visit for EC was not their first visit). Again, over $80 \%$ were using condoms. First time EC users were somewhat more likely to report using contraceptive pills than repeat users: $22.1 \%$ compared to $13.8 \%$ (Tables not shown).

These results should be treated with some caution. Women may choose to enhance their use of contraception because they feel that the clinic nurses and doctors may be disapproving of their not using regular contraception. Clients may also interpret the question asked ("Are you using any contraception at the moment?') to mean 'what do they regularly use?', not what they used at last intercourse.

Clients were asked why they needed EC 'today'. In contrast to the $15.2 \%$ reporting that they were not currently using some form of contraception, a larger percentage $(28.6 \%)$ reported that 'no contraception was used' (Table 5 ). Half reported a condom mishap and about $10 \%$ reported 'missed pills'. The youngest and oldest age groups were more likely to report using no contraception.

Asking women why EC is needed, on the day, may be a sensitive question for all users, but may be particularly 
Table 5 Why need EC, by age

\begin{tabular}{lcccccc}
\hline & \multicolumn{5}{c}{ Age (years) } \\
& $\mathbf{1 4 - 1 7}$ & $\mathbf{1 8 - 1 9}$ & $\mathbf{2 0 - 2 4}$ & $\mathbf{2 5 - 2 9}$ & $\mathbf{3 0 +}$ & Total \\
\hline $\begin{array}{l}\text { Why Need EC } \\
\text { No contraception } \\
\text { used }\end{array}$ & 56 & 32 & 31 & 20 & 21 & 160 \\
& $35.4 \%$ & $25.4 \%$ & $21.8 \%$ & $26.7 \%$ & $35.6 \%$ & $28.6 \%$ \\
Condom split & 81 & 62 & 74 & 41 & 30 & 288 \\
& $51.3 \%$ & $49.2 \%$ & $52.1 \%$ & $54.7 \%$ & $50.8 \%$ & $51.4 \%$ \\
Missed pills & 8 & 16 & 17 & 5 & 4 & 50 \\
& $5.1 \%$ & $12.7 \%$ & $12.0 \%$ & $6.7 \%$ & $6.8 \%$ & $8.9 \%$ \\
Other & 12 & 11 & 16 & 8 & 4 & 51 \\
& $7.6 \%$ & $8.7 \%$ & $11.3 \%$ & $10.7 \%$ & $6.8 \%$ & $9.1 \%$ \\
Multiple & 1 & 5 & 4 & 1 & - & 11 \\
& $0.6 \%$ & $4.0 \%$ & $2.8 \%$ & $1.3 \%$ & & $2.0 \%$ \\
TOTAL & 158 & 126 & 142 & 75 & 59 & 560 \\
& $100.0 \%$ & $100.0 \%$ & $100.0 \%$ & $100.0 \%$ & $100.0 \%$ & $100.0 \%$ \\
\hline & & & & & &
\end{tabular}

sensitive for repeat users, who may feel that they have to justify their need to use an 'emergency' contraceptive method yet again. Asked the number of hours elapsed since unprotected sex, the great majority of respondents reported fewer than 48 hours (Table 6). Only $4 \%$ of respondents reported more than 72 hours. However, a fifth reported an elapsed time of 49-72 hours, although evidence suggests that the efficacy of PC4 is higher when given in the first 24 hours. ${ }^{4}$ There is variation by age group and these data show that nearly $30 \%$ of the youngest women (14-17) do not seek EC for more than 48 hours. In contrast this is the case for fewer than $20 \%$ of those aged 18-19. This may reflect the fact that the youngest group have less control over their ability to access EC than those even slightly older.

Elapsed time since unprotected sex was not significantly different for repeat and first time users.

Table 6 Number of hours since unprotected sex, by age

\begin{tabular}{|c|c|c|c|c|c|c|c|}
\hline & & & & ge (years) & & & \\
\hline & & $14-17$ & 18- 19 & $20-24$ & $25-29$ & $30+$ & TOTAL \\
\hline Hours & $1-24$ & 70 & 55 & 59 & 28 & 27 & 239 \\
\hline & & $47.0 \%$ & $47.0 \%$ & $42.4 \%$ & $38.9 \%$ & $48.2 \%$ & $44.8 \%$ \\
\hline & $25-48$ & 37 & 40 & 46 & 27 & 16 & 166 \\
\hline & & $24.8 \%$ & $34.2 \%$ & $33.1 \%$ & $37.5 \%$ & $28.6 \%$ & $31.1 \%$ \\
\hline & $49-72$ & 35 & 18 & 32 & 13 & 9 & 107 \\
\hline & & $23.5 \%$ & $15.4 \%$ & 23.0 & $18.1 \%$ & $16.1 \%$ & $20.1 \%$ \\
\hline & $73+$ & 7 & 4 & 2 & 4 & 4 & 21 \\
\hline & & $4.7 \%$ & $3.4 \%$ & $1.4 \%$ & $5.6 \%$ & $7.1 \%$ & $3.9 \%$ \\
\hline TOTAL & & 149 & 117 & 139 & 72 & 56 & 533 \\
\hline & & $100.0 \%$ & $100.0 \%$ & $100.0 \%$ & $100.0 \%$ & $100.0 \%$ & $100.0 \%$ \\
\hline
\end{tabular}

Perceptions of how often EC is safe to use

Respondents were asked how often they felt EC was safe to use. Half said it was only safe to use once or twice a year (Table 7). Over a fifth of respondents said it was safe to use once a month or more. Amongst the youngest age group, $36 \%$ said it was safe to use as frequently as this. Responses for repeat users were not significantly different than those for first time users. While current evidence suggests that repeat use of EC is safe, women who are seeking it repeatedly within a short time period are exposed to a greater risk of pregnancy than those using a more reliable, non-emergency, method, and may be demonstrating a need for help in finding another method.

Table 7 How frequently can EC safely be used, by age

\begin{tabular}{|c|c|c|c|c|c|c|}
\hline & \multicolumn{5}{|c|}{ Age (years) } & \multirow[b]{2}{*}{ TOTAL } \\
\hline & $14-17$ & 18- 19 & $20-24$ & $25-29$ & $30+$ & \\
\hline $\begin{array}{l}\text { More than } \\
\text { once a month }\end{array}$ & $\begin{array}{c}13 \\
10.4 \%\end{array}$ & $\begin{array}{c}6 \\
5.8 \%\end{array}$ & $\begin{array}{c}5 \\
4.2 \%\end{array}$ & $\begin{array}{c}3 \\
5.1 \%\end{array}$ & $\begin{array}{c}1 \\
2.2 \%\end{array}$ & $\begin{array}{c}28 \\
6.2 \%\end{array}$ \\
\hline Once a month & $\begin{array}{c}32 \\
25.6 \%\end{array}$ & $\begin{array}{c}20 \\
19.2 \%\end{array}$ & $\begin{array}{c}14 \\
11.9 \%\end{array}$ & $\begin{array}{c}2 \\
3.4 \%\end{array}$ & $\begin{array}{c}4 \\
8.9 \%\end{array}$ & $\begin{array}{c}72 \\
16.0 \%\end{array}$ \\
\hline $\begin{array}{l}3 \text { or } 4 \text { times } \\
\text { a year }\end{array}$ & $\begin{array}{c}35 \\
28.0 \%\end{array}$ & $\begin{array}{c}34 \\
32.7 \%\end{array}$ & $\begin{array}{c}27 \\
22.9 \%\end{array}$ & $\begin{array}{c}19 \\
32.2 \%\end{array}$ & $\begin{array}{c}7 \\
15.6 \%\end{array}$ & $\begin{array}{c}122 \\
27.1 \%\end{array}$ \\
\hline $\begin{array}{l}\text { Once or twice } \\
\text { a year }\end{array}$ & $\begin{array}{c}45 \\
36.0 \%\end{array}$ & $\begin{array}{c}44 \\
42.3 \%\end{array}$ & $\begin{array}{c}72 \\
61.0 \%\end{array}$ & $\begin{array}{c}35 \\
59.3 \%\end{array}$ & $\begin{array}{c}33 \\
73.3 \%\end{array}$ & $\begin{array}{c}229 \\
50.8 \%\end{array}$ \\
\hline TOTAL & $\begin{array}{c}125 \\
100.0 \%\end{array}$ & $\begin{array}{c}104 \\
100.0 \%\end{array}$ & $\begin{array}{c}118 \\
100.0 \%\end{array}$ & $\begin{array}{c}59 \\
100.0 \%\end{array}$ & $\begin{array}{c}45 \\
100.0 \%\end{array}$ & $\begin{array}{c}451 \\
100.0 \%\end{array}$ \\
\hline
\end{tabular}

\section{Discussion}

For the purposes of this study, repeat users are those who have used EC, prior to the audited visit for EC, at least once either 'ever' or in the study year. In contrast to previous research, this study shows high levels of repeat use, whether measured as 'ever use' $(66.8 \%)$ or use within the study year $(52.2 \%)$. This high level of use in the study year contrasts sharply with the annual estimates of repeat use reported by Rowlands et al; ${ }^{1}$ about $14 \%$ of EC users used EC more than once.

This study also found high levels of repeat use across age groups; repeat use is not confined to the very young or to teenagers. The great majority of first time and repeat users report currently using a method of contraception, and most report using condoms. However, asked why EC is needed on the day, nearly a quarter report having unprotected sex. The large number of reported condom mishaps suggests the possibility that some women feel they must give what is perceived as an acceptable response to the health professional in answer to why EC is needed.

The generalisability of these findings will have to await further research. Informal discussion with a number of other FPC doctors also suggests high levels of repeat use. (A proposal for a national study carried out by the UK Family Planning and Reproductive Health Network and Exeter University is currently being considered for funding.) There are, of course, limitations to these data. Medical records, where carefully maintained, will provide more accurate data than a survey which, for some women, requires recall over several years. But medical records provide a more limited range of measures. They do not include the attitude data which this survey sought, and would not include some of the background measures used in this study. While recall questions, as used in this study, may have inaccuracies, these are likely to be in the direction of underestimating EC use. As Rowlands et al note, relying only on GP data to estimate repeat use of EC has limitations; most importantly these records may not include use of other contraceptive service providers. GPs are not routinely informed of their patients' EC use in this district, as EC is a safe medication and the volume of prescribing precludes notification. And if first time EC users use their GP, while repeat users shy away from this service for fear of a censorious response or for other reasons as discussed below, these data will significantly underestimate repeat use. 
The level of knowledge about EC, the time period for using it, and its availability is high amongst even the young in North and East Devon, although less so amongst young boys. ${ }^{6}$ There are also area guidelines for FPCs and GP practices, primarily for receptionists, to enhance sensitivity in booking emergency appointments. However, the recent research on use of sexual and reproductive health services in the area shows the barriers to use of the GP, including getting past the receptionist and being seen by friends, parents and friends of parents (problems which are exacerbated in small communities) as well as fears about confidentiality. ${ }^{7}$

Ziebland's ${ }^{8}$ analysis of the attitudes of GPs towards EC prescribing may go some way in explaining the differences between the Rowlands study ${ }^{1}$ and the present study. This GP study included a sample selected from the GP lists of three health authorities. Tape recorded telephone interviews were conducted with 76 GPs. Although de-regulation of EC was the focus of the interviews, what emerged was the ambivalence of many GPs to repeat use of EC and judgmental attitudes on the part of some. Responses ranged from a felt need to 'exert gentle pressure' to find a more reliable method of contraception to giving 'her a bollocking and tell her to get her act together' or 'impress on her that she needs to be more responsible'. Only one GP suggested that there might be some good reason why a patient might not have chosen to use regular contraception. Asked how often they were 'happy to prescribe' EC to the same woman in a year, only $23 \%$ of the GPs interviewed said that they would 'be happy to' provide it as often as requested.

Ziebland ${ }^{8}$ argues that the responses from GPs both to deregulation and repeat use of EC may 'reflect a tension between the public health response to the high incidence of unwanted pregnancies and the GPs focus on the contraceptive needs of the individual patient'. However, this ignores the dilemma which GPs, FPCs and other EC providers all face in creating an environment which is both supportive of EC use, including repeat use, and which attempts to advise women on other contraceptive methods. These two foci of health care are at odds with each other. It is also the case that the 'emergency' needs for EC are at odds with having a more extended appointment with the doctor or nurse in which a woman's sexual relationships and contraceptive options may be explored in a way which gives support to even the youngest women.

The differences between rates of EC use and repeat use amongst providers will reflect, for most women, the degree to which the provider is perceived as an accessible and nonjudgmental source of EC. Issues related to de-regulation of EC should be put in this context.

Statements on funding and competing interests

Funding. Funding was provided by the North and East Devon Health Authority and the School of Postgraduate Medicine and Health Sciences, University of Exeter.

Competing interests. None.

References

Rowlands S, Devalia H, Lawrenson R, et al. Repeated use of hormonal emergency contraception by younger women in the UK. Br J Fam Plann 2000; 26 (3):138-143. Department of Health. Statistical Bulletin 1999/30. NHS Contraceptive Services, England: 1998-99. London: Stationery Office, 1999.

North and East Devon District Interface Audit Group. Report on the interface re-audit of Emergency Contraception, 2000. Exeter: North and East Health Authority, 2000.

Kubba A, Wilkinson C. Recommendations for clinical practice: emergency contraception London: Faculty of Family Planning and Reproductive Health Care, 1998.

Seamark CJ, Pereira Gray DJ. Teenagers' use of emergency contraception in a general practice.

339: $1-4$.

G39: 1-4. . Ayres R, Owen MR, et al. Drop-in clinics for teenagers in primary care: a controlled trial to determine their acceptability, effectiveness and cost. Working Paper No. 31, Institute of Population Studies, University of Exeter, 2000

8 Ziebland S. Emergency contraception: an anomalous position in the family planning repertoire? Social Science \& Medicine 1999; 49: 1409-1417. 